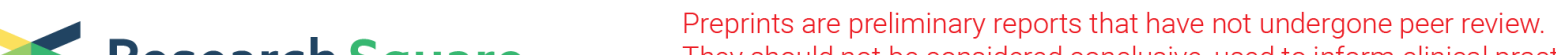 Research Square They should not be considered conclusive, used to inform clinical practice, or referenced by the media as validated information.
}

\section{"The Underground Water Sources were Contaminated" A Qualitative Assessment of the Spread of Typhoid Fever in Kampala City, Uganda}

\section{Lynn Atuyambe}

Department of Community Health and Behavioural Sciences, School of Public Health, Makerere University

Edwinah Atusingwize ( $\nabla$ eatusingwize@musph.ac.ug)

Makerere University School of Publich Health https://orcid.org/0000-0001-8701-5608

\section{Christine Nalwadda Kayemba}

Department of Community Health and Behavioural Sciences, School of Public Health, Makerere University

Research article

Keywords: Typhoid, outbreak, Uganda, Kampala, water, contaminated, underground wells

Posted Date: December 8th, 2020

DOI: https://doi.org/10.21203/rs.3.rs-122518/v1

License: (c) (i) This work is licensed under a Creative Commons Attribution 4.0 International License. Read Full License 


\section{Abstract}

Background: Globally, approximately 11-21 million people get typhoid fever annually. The disease is characterized by prolonged fever, headache, nausea, loss of appetite, and constipation or diarrhoea and the transmission is oral-faecal. In early 2015, the Uganda Ministry of Health, confirmed typhoid fever outbreak in Kampala city which quickly spread to the neighbouring districts. Strategies including preventive and curative measures were put in place to control the disease although the outbreak persisted and spread quickly. In response, this study was commissioned to identify risk factors that propagated the outbreak in Kampala and the surrounding districts, and to establish innovative ways of communicating risk and behavioural change messages to the populations at risk.

Methods: This was a qualitative study among residents working in major food markets of Kampala, Mukono and Wakiso districts. Data was collected using 14 focus group discussions (FGDs), 25 Key Informant Interviews (KIIs), 10 In-depth Interviews (IDIs), and environmental observations within communities including major markets. A total of 10 FGDs from Kampala district were stratified by sex while the 4 FGDs conducted in Mukono and Wakiso districts were mixed by sex. Data was analysed employing the thematic approach using open codding.

Results: Behavioural practices, environmental, health system and policy related factors propagated the outbreak. We established that poor personal and food hygiene, contaminated water sources, consumption of unsafe beverages, the prolonged dry season, inadequate disease surveillance and delay in diagnosis and treatment of cases were main factors that led to the outbreak. Our study established that the behaviour change approaches were electronic, media, print and face to face communication. These strategies created an understanding of the presence of the outbreak but had some limitations. The study highlighted major recommendations for future control of typhoid outbreak included innovative use of technology and intersectoral collaborations.

Conclusion: Typhoid outbreak was spread through individual behavioural, environmental and health system factors. Innovative communication strategies including use of mobile technologies, school children as messengers, strengthened face to face communication by community leaders and expressing messages in terms of economic losses and gains were recommended.

\section{Background}

Globally, an estimated 11-21 million people suffer and 128,000-161,000 die from typhoid fever annually with higher mortality estimates in low income countries (WHO 2018, Stanaway, Reiner et al. 2019). Typhoid fever is caused by the bacterium Salmonella Typhi found in the blood stream or in the intestinal tract. The disease is characterized by prolonged fever, headache, nausea, loss of appetite, and constipation or sometimes diarrhoea (WHO 2018). Typhoid fever is spread through consumption of water or food contaminated with faecal matter (oral-faecal transmission). The risk factors for typhoid fever include; lack of access to safe water, poor housing, inadequate food hygiene, poor disposal of human 
excreta, inadequate personal hygiene such as poor hand practices before eating (Gasem, Dolmans et al. 2001, Vollaard, Ali et al. 2004).

Evidence from systematic reviews indicate that typhoid outbreaks have been reported in several African countries (Watson, Basnyat et al., Mogasale, Maskery et al. 2014, Kim, Im et al. 2019). In Uganda, the disease outbreak was previously reported in the district of Kasese, characterised by a high rate of intestinal perforation (Neil, Sodha et al. 2012, Carias, Walters et al. 2015). In Kampala particularly in slums, the hygiene and sanitation are poor mainly due to high demand of related facilities. Shared toilets, public toilets, and open defecation are common (Tumwebaze, Orach et al. 2013) exposing most of the population.

The Uganda Ministry of Health confirmed typhoid fever outbreak on the 19th of February 2015 in Kampala city which quickly spread to the neighbouring districts of Wakiso and Mukono. By 5th of March 2015, there were 1940 cumulative suspected cases with 111 new confirmed cases (WHO 2015) (Kabwama, Bulage et al. 2017). Following the outbreak, strategies were put in place to control the spread of the disease. These strategies included preventive measures through health education using the mass media (print, television, and radio), and curative measures by establishing treatment centres. However, the outbreak was persistent with the number of new cases (suspected and confirmed) continuing to rise. This study was therefore commissioned to identify behavioural risk factors that were propagating the typhoid outbreak in Kampala and the surrounding districts, and to establish innovative ways of communicating risk and behavioural change messages to the populations at risk.

\section{Methods}

\section{Study design and population}

This qualitative study was conducted in the five divisions of Kampala (Kawempe, Nakawa, Central, Makindye, and Rubaga) and neighboring districts of Wakiso and Mukono in March and April 2015. Kampala is Uganda's capital and business center (approximately 1.5 million people/residents and four million day-time population) surrounded by rapidly growing commercial and residential districts (UBOS 2015).

\section{Data Collection Methods And Sample Size}

Key Informant Interviews (KIIs), In-depth Interviews (IDIs), community observations, and focus group discussions (FGDs) were conducted among residents working in the main food markets in each of the study districts. Overall, we conducted 14 FGDs (10 from Kampala district stratified by sex while the 4 conducted in Mukono and Wakiso districts were mixed by sex). A total of twenty five KIls (at national and sub-national level/District) were conducted. Participants were community leaders, health care providers in health facilities, health managers at district and national levels, and officials in relevant government departments. Ten IDIs were conducted with selected typhoid patients to obtain their experiences and 
opinions about factors that enhanced the spread of typhoid. These patients were obtained from the health units. Additionally, observations were made in the same communities where FGDs were conducted to observe environmental factors that could have been related to the outbreak. Observations were made on the: type and location of available water sources, presence of human waste in the surroundings; and food and water handling practices. Data were collected using experienced research assistants who were trained about the study objectives and procedures. All tools were pretested, and corrections made accordingly prior to data collection.

Study tools were focused on the: a) main behavioural risk factors responsible for the spread of typhoid fever in Kampala and the surrounding districts. Knowledge on transmission of the disease, food safety and hygiene, feeding practices, sanitation situation, water sources, and perceived water safety from various sources were explored. b) The novel ways that could be utilized to best communicate information for behavioural change in the community were explored. We assessed the existing typhoid related behavioural change messages to the populations at risk, and the communication channels that were being used to disseminate typhoid related behavioural change messages to the populations at risk.

\section{Data management}

All the audio recorded interviews and discussions were transcribed verbatim. Notes from interviews that were not recorded, were expanded (written out removing abbreviations and shorthand symbols) immediately after the interviews. Where the need arose, clarity was obtained from the respective study participants.

Data analysis was conducted using thematic approach. A master sheet (data log) was developed in MS Excel and transcripts were labelled by data collection method in different Excel tabs. The transcripts were read several times and the open codding approach was used to generate the initial list of codes. As the transcripts were re-read several times, some new codes were created or added to the existing list of codes. The generated codes were condensed into categories (sub-themes) which were finally merged into themes. The process of categorizing codes into theme was a repetitive process including re-reading the transcripts and editing appropriately in order to refine the themes and ensure that the emerging themes were grounded in the data (O'Connor et al 2003) and (Graneheim \& Lundman, 2004). The research team reviewed and agreed upon the codes, categories, and themes.

\section{Ethics approval:}

The study was approved by the Uganda Ministry of Health. Further permission was sought from the district health offices and the management of the respective health facilities where the recovering patients were found. Study objectives, benefits and risks were explained to the study participants. We sought written informed consent from all study participants and endeavoured to observe confidentiality.

\section{Results}


Our results are presented in three thematic areas: I) Community understanding of typhoid, II) Factors propagating typhoid and III) Strategies implemented to control typhoid outbreak

I) Community understanding of typhoid: The community understanding of typhoid was explored in terms of cause, symptoms, and prevention of typhoid.

\section{Understanding of cause and symptom}

Majority of IDIs and FGDs participants believed that typhoid was caused by poor personal hygiene, consumption of unsafe food, water, and beverages. Some participants also said that typhoid was caused by poor environmental hygiene such as littering with garbage, open defecation, leaking and or blocked drainage systems. A few misconceptions were also established. In almost a half of FGDs, a few participants perceived that typhoid was an air borne disease, caused by fog, and affected only specific nationals. All the $25 \mathrm{Kls}$ knew the cause of typhoid; Salmonella Typhi.

Overall, FGDs and IDI participants were aware of signs and symptoms of typhoid (including fever, headache, stomach-ache, and fever that did not respond to malaria treatment). Other symptoms mentioned were general body weakness, joint pains, diarrhoea, vomiting, loss of weight and nausea. Knowledge of symptoms was from participants' observations of typhoid patients, health education from the various communication channels, and lived experiences by recovering patients.

"Signs of typhoid are prolonged fever, after you have treated malaria for a long time, and it doesn't cure you start suspecting that you might have typhoid. If you treat a child for malaria and you see the child is not recovering, you just know there is a problem (Female FGD, District Level- Kampala, Rubaga Division)".

"I felt my health was not as usual. I had fever, stomachache, headache, I lost my appetite, I was feeling pain in the joints and the back, so I decided to go for medical care" (IDI-Recovering patient, Kampala District, Central Division)

\section{Understanding of prevention of typhoid}

We also assessed participants' knowledge about typhoid by asking them about how the disease could be prevented. Most FGDs emphasized the need for community sensitization on improving personal, food and water hygiene both at work and homes. Participants also noted that typhoid could be controlled by regulating food market including screening food handlers for typhoid and providing safe water sources. In addition, reduction of water costs, proper human and solid waste management and isolation of typhoid patients were thought to prevent typhoid. Kls also noted that provision of proper care for the sick, integrated improvement of sanitation and housing infrastructure are important in decongesting the city especially informal settlements.

Both short and long term strategies for typhoid control were also emphasized by three quarters (19) of the Kls. The short-term strategies suggested included vaccination of populations at risk against typhoid, and promotion of good hygiene practices like hand washing. In the long term, they said that preventing 
further spread of typhoid in Kampala and other urban areas should involve aggressive improvements in access to sustainable safe water and sanitation. The role of developing or updating and implementing different regulations in preventing occurrence of disease was also stressed. They said that regulations such as policies regarding handling safe water, sewerage systems, marketing or sale of food and beverages, and wider public health issues including collaborations among sectors should be emphasized.

"There is need to review the Public Health Act, 2006 and aggressively implement it as well as speed up drafting the proposed Food and Drugs Policy and thereafter its enforcement. That will enhance regulation of public health activities in the city" (KI, National level)

All Key Informants emphasized that an innovative and functional Health Management information System (HMIS) could prevent typhoid outbreak by providing early warning information to detect possible epidemics. A national level KI stressed that if all health facilities submitted accurate real time data, appropriate time trend-analysis could be used for early detection of typhoid outbreak through defined alert thresholds. The need for a multi-disciplinary outbreak response team including various experts such as epidemiologists and social scientists was emphasized. All KIs believed that with proper resource mobilisation at national, district and village levels, a well-coordinated multidisciplinary response team could potentially reduce the disease spread and case fatalities.

"A Rapid Response Team (RRT) composed of Epidemiologists, laboratory technicians, behavioural scientists (medical anthropologist), veterinary officers, environmental health officers and other persons with relevant specialties all responsible to trigger timely actions like verification, investigation and outbreak response will help to limit typhoid disease spread and reduce case fatalities"(KI, National level)

\section{II) Factors Propagating Typhoid Fever}

The factors propagating the outbreak were categorised into behavioural practices, environmental and health system factors.

\section{Behavioural practices}

Focus Group Discussions and Key Informant interviews showed that several individual practices including poor personal hygiene such as common failure to wash hands after visiting the toilet contributed to the outbreak. Widespread poor feeding practices like consumption of un-boiled water, half boiled tea, cold foods from street vendors, and cold drinks including locally packed juices prepared with unsafe water were reported. One of the leaders had this to say

"this vending of juices, locally packed water in buveeras [plastic bags] and other containers, I think that could be one of the reasons [for continued spread] and even these street fruits much as we have not done any testing to confirm that the fruits are the cause but the water used to wash the fruits is contaminated" (KI, District Level- Kampala, Central Division ) 
"I mean water and juice locally packed; our people are not honest. Other people have told us to avoid bottled water because it may not be safe and that's where typhoid might pass to affect us" (FGD-Mixed Sex, District Level- Wakiso)

Environmental factors: The environmental factors propagating the outbreak were mainly related to sanitation, water supply, and commercial activities. Open defecation, poor solid waste disposal, lack of hand washing facilities in public toilets, leaking sewage and blocked drainage were common and believed to be part of the drivers of the epidemic. Business centres especially the capital city was much affected.

"I first heard about this in a business centre where sewage pipes got leakages and got mixed with water pipes and contaminated the water... when the rain comes people unblock their toilets and sewage contaminates water" (FGD-Mixed Sex, District Level-Mukono)

Shortage of safe water from National Water and Sewerage Cooperation (NWSC) was a critical factor echoed by majority of the Kls and all FGDs. Contaminated water sources mainly wells and springs were blamed for the outbreak. Many participants revealed that people obtained water from several water sources including un-protected springs and wells reportedly contaminated with E. coli.

"although Kampala is supplied with national piped water, there are other water sources like wells and springs, protected and unprotected. The protected springs were safe but there were a number of them contaminated. Two of the three unprotected wells tested were contaminated" (KI, National level).

"typhoid is mostly in towns because it is where there is lots of congestion, hygiene is poor, there are people who don't have toilet, they just defecate wherever they want, sometimes those toilets we have talked about collapse and they will flood over drainage channels, contaminating water sources" (FGDMale, District Level- Kampala, Makindye division)

This study also established a unique practice by landlords in Kampala city that was believed to be the source and spread of typhoid. The practice was said to be a strategy for evading payment of water bills to National Water and Sewerage Cooperation (NWSC). Participants were concerned about the construction of underground wells by landlords to supply water to large commercial buildings instead of the recommended piped water supply provided by the NWSC. Unfortunately, such wells were reportedly heavily polluted with faecal matter.

"In our arcades, (shopping malls) we have wells instead of NWSC and these wells mix up with sewage which contaminates this water. This water is pumped from the well and pumped to the water tank and then supplied in the whole arcade and we use it. There was someone from KCCA who talked on radio and he said that he got water from these wells and tested it in the lab. He mentioned that $70-90 \%$ of the underground water sources were contaminated with faeces which he said was one of the causes of this disease" (FGD-Male, District Level- Kampala, Central Division). 
Commercial activities such as hawking of locally made beverages including counterfeit bottled water, repackaging branded bottles with unsafe water was believed to propagate the disease. Other commercial practices aimed at saving operation costs involved food vendors and restaurant owners contracting supply of locally packed juices and boiling of drinking water to third parties who reportedly supplied unsafe products. The prolonged hot and dry season at that time reportedly increased the demand for drinking water. The increased demand and market for various cold drinks, created an opportunity for some vendors to sell unsafe drinks.

"with the prolonged drought, it was really hot...that caused an increased need to drink, so the drinks become very marketable, so the sellers begun to make short cuts. Scarcity of water that comes with the drought causes people now to go to the unsafe sources of water" (KI, National Level).

There were also some community beliefs and cultures that could have had key consequences on how individuals and communities responded to the various messages to control the outbreak. For instance, some community members reportedly believed that children feaces were regarded not as dangerous as adult feaces. Other strong cultural beliefs and poor attitudes were reported in relation to persistent use of unsafe water especially from unprotected shallow wells and springs. Springs had always been the main source of water in many areas originally not covered by the national water supply system. Kls noted that it was difficult to stop communities from using the traditional sources which often would be unsafe especially in the face of rapid urbanization. Several Key Informants pointed out that some communities used spring water because normally it was free or associated with very low cost and believed to be safe for drinking.

"people's behaviours and attitudes are very bad, if you look at the household level-the way they cook, how they keep their water and of course using that spring water because even when you tell them that 'please let us use that water for washing only, they tell you that we have taken that water for years and nothing has happened, so why the danger today?" (KI, District Level-Kampala, Nakawa)

The environmental observations were made in communities and five major markets in the study districts using a checklist with hygiene indicators. Observations showed poor sanitation and food hygiene which could have contributed to the causes and spread of typhoid disease (Fig. 1).

Scattered cooking utensils some of the water sources

Market littered with solid waste Open shallow well

\section{Health system factors}

Health system factors were related to policies and delivery of services at health facilities. The Kls at health facility and national level indicated that factors related to health care delivery such as inadequate supplies, personnel and surveillance also played an important role in propagating the outbreak. First line medicines were thought to have developed drug resistance, and lack of laboratory confirmatory 
investigations resulted into delays in treatment of typhoid patients. All Kls also reported that the designated health facilities were overwhelmed with patients given that health workers were few, and in some cases without the necessary competence. The case definition of typhoid reportedly had low specificity and sensitivity limiting proper and timely diagnosis. In addition, national level Kls noted that private health facilities were not keen on sending data to the national database making disease surveillance inadequate.

"At first [mentions facility] was the only centre for management but due to the high number of patients. With few health workers, we were advised by the government to open the other centres for KCCA... One of the challenges is the testing supplies..., actually we were using it, tubex, routinely until when we were told it is very expensive and we run out of it, so we are actually not using it any more. We are relying on the case definition which is not very specific" (KI, District Level- Kampala, Central Division).

There were also contextual issues related to policy that were reported as critical in the spread of the disease. Strong views were noted on a weakened health inspectorate domain due to the restructuring policy which reduced number of health inspectors and assistants in the capital city. This was believed to negatively affect the occurrence of the necessary health inspections in communities. In addition, the lack of an established rapid response team within in the capital city authority challenged the coordination activities for the control of the outbreak.

The other factor believed to propagate the outbreak was the unclear mandate of line ministries. For instance, most Key Informants were concerned that safe water supply and human waste management are key elements in the occurrence of typhoid but are not in the core mandate of the Ministry of Health. The dominant opinions were that the Ministry of Health found it challenging to address these key elements. There were also strong views among Key Informants regarding an imbalance in funds provided for prevention programs versus curative services, leading to preventable epidemics including typhoid. Other issues that were raised included corrupt law enforcement personnels issuing trading licenses to traders who did not fulfil the necessary public health requirements.

\section{III) Communication Strategies Implemented To Control Typhoid Out Break}

\section{Communication channels}

Nearly all interviews and group discussions indicated that print and electronic media including announcements on radios, television, and public address system were used to communicate typhoid outbreak. Participants reported that there was also one-to-one communication approach, which was reported as a more preferred means for un-packaging the messages at household level than general media announcements. 
"the radio-customized announcement or message cannot address, cannot sense the community attitudes and perceptions in every household. But when the officer enters into the household, he will be in position to re-package the message properly" (KI, District Level-Wakiso)

Generally, the messages mainly focused on alerting people about presence of the outbreak, signs and symptoms, means of transmission as well as prevention of typhoid disease. All participants also said that the messages encouraged communities to report suspected cases of typhoid and seek appropriate care in the health facilities. However, communication gaps were observed for instance in messages regarding 'what causes the typhoid'. Interviews revealed that the messages emphasized 'not eating and drinking cold food'. This raised concerns given that some foods and drinks (especially fruits) are naturally taken cold. Furthermore, the messages were only in English and Luganda languages which excluded other communities available in a multilingual city such as Kampala.

\section{Innovative communication approaches}

Generally, participants proposed simple effective ways of communicating to the public. They proposed use of community structures such as Local Council (LCs), Red Cross volunteers; and Village Health Teams (VHTs) and school children to disseminate information in communities. Other proposed strategies that were innovative included use of media such as: mobile vans within communities, announcements on megaphones in markets (which had gained popularity); and local community radios involving distinguished persons in messages clips. Sending of mass messages through SMS (short message service) with support from Uganda Communication Commission was also believed to be an accessible and acceptable approach. In addition, there was strong advocacy for interactive messaging response (IMR) and interactive voice response (IVR). IVR refers to a technology that allows a computer to interact with humans through the use of voice, allowing clients or patients to interact with a host system via a telephone keypad or by speech recognition. IVR systems can respond with pre-recorded or dynamically generated audio to further direct users on how to proceed (Crawford, Sikirica et al. 2005, Dillman, Phelps et al. 2009).

The participants cited other strategies for preventing the outbreak including active surveillance, and intersectional collaboration. More investment in health promotion with consideration of health messages designed in terms of potential expenses and or costs averted was also recommended. For instance, they advocated of preventive messages that not only talk about the disease (typhoid) but also show how much money would be saved or costs averted by an individual following preventive messages such as boiling all water for drinking. One Key Informant also highlighted the need to pay attention to broader urban health issues to ensure general improvements in housing, water, sanitation, and hygiene.

"the whole issue of urban health services is another big picture... the urban health issues pose a very big challenge in terms of overcrowding, inadequate sanitation, provision of safe water and fuel" (KI, National Level)

\section{Discussion}


Generally, knowledge gaps in community's understanding of typhoid fever were reported. The factors that were propagating the outbreak were related to behavioural practices, environmental, health care delivery and policy concerns. Communication strategies that were implemented to control the typhoid outbreak, had gaps including failure to send out messages in various languages, an important aspect of communication in a multilingual society. Innovative communication strategies were recommended to support control of the outbreak.

There were some community misconceptions about typhoid fever, an indicator of inadequate understanding among community members about the disease, which has been shown to be a risk factor for such an outbreak (Alba, Bakker et al. 2016). Participants emphasized the need to strengthen community sensitization on hygiene as a strategy to prevent typhoid fever. Indeed, community sensitization has been an effective strategy in preventing similar outbreaks including filoviral haemorrhagic fever (Vanessa and Matthias 2012). Participants believed that the outbreak was propagated by inadequate personal hygiene practices which were common such as not washing hands at critical times, a risk factor for cause and spread of typhoid fever (Alba, Bakker et al. 2016) (Greenwell, McCool et al. 2013, Prasad 2015). The described environmental factors including poor sanitation and contaminated water sources (Murphy, Kahler et al. 2017) are important in the spread of such diseases (Walters, Routh et al. 2014), (Muti, Gombe et al. 2014). Also, the health care delivery factors such as the reported inadequate personnel, supplies, and surveillance system are critical in the control of outbreaks (Tambo, Ugwu et al. 2014).

Other factors propagating the outbreak were contextual in terms of policy and cultural beliefs. Such issues significantly influence design and implementation of efficient and acceptable key prevention activities in various communities. Policies create a favourable environment for availability of funds, personnel and structures necessary for prevention and control of diseases (Bunnell, O'Neil et al. 2012). Cultural beliefs and related attitudes have been implicated in the spread of other outbreaks globally, and can challenge many community interventions when they are not addressed (Manguvo and Mafuvadze 2015).

One of the strategies to prevent and control the outbreaks is risk communication. We however found that there were communication gaps which could have negatively affected how communities received, understood and responded to messages regarding the risk (O'Connor, O'Sullivan et al. 2009). The use of community structures including VHTs was rightfully recommended. The contribution of VHTs to the health system including efforts during disease outbreaks has been recognised elsewhere (Mbonye, Wamala et al. 2014) and should be leveraged during such epidemics. Innovations in communication were proposed, including use of modern mass communication strategies such as IMR and IVR which have been used in other community interventions (Dowshen, Kuhns et al. 2013, Osborn and Mulvaney 2013). Such technology-based approaches may sometimes require high initial capital investments but may have significant benefits in the long run. Besides $m$-health, communication interventions should explore use of common emerging communication channels such as social media used by majority of urban dwellers. 
Social media could potentially serve various purposes in real time including assessing and addressing the public's sentiments, feelings and risk perception (Tang, Bie et al. 2018, Oh, Lee et al. 2020).

Communicating messages on risk in terms of costs was also suggested to highlight potential financial consequences that can easily trigger a desired individual practice as a response to avert such costs. Such messages could for instance quote/highlight, "how much costs can be prevented by adopting appropriate hand washing practice at critical times. Design of actual messages that 'demystify' misconceptions is also important. For instance, messages such as 'typhoid is not caused by air, but faecal contamination of water and food'. However, it is important to package the message using locally acceptable words or phrases and not a mere translation of scientific terms. Other strategies should focus on investment in health promotion, intersectional collaboration, use of children to convey messages in communities, and implementing an improved active surveillance system. Active surveillance has shown positive results for other outbreaks interventions (Chitnis, Caruthers et al. 2012, Silwedel, Vogel et al. 2016) and communicating messages through school children is a recognised strategy in sanitation and other prevention strategies in many communities (Onyango-Ouma, Aagaard-Hansen et al. 2005, Mwanga, Jensen et al. 2008, Gadhoke, Christiansen et al. 2014).

\section{Strength and Limitations}

This was a cross sectional study that cannot show causal relationships. The study however presents a qualitative understanding of behavioural risk factors that played a key role in the cause and spread of the outbreak. Major recommendations that should be explored for the control of future typhoid and similar outbreaks have been highlighted from the community perspective.

\section{Conclusion And Recommendations}

Behavioural practices, environmental, health care delivery and policy related factors were critical in the spread of typhoid outbreak. Commercial practices related to contaminated underground water; food and beverages sold by market and street vendors should be regulated by urban authorities. The communication strategies created and enhanced the awareness of the presence of typhoid disease although there were a few communication gaps. We recommend innovative technology approaches that should be explored such as use of IMR and IVR communication on phones targeting cultural beliefs. Messages on disease risk during such outbreaks should be expressed in terms of economic losses and or gains related to a desired practice. The Ministry of Health, the district and city authorities should also strengthen inspections, surveillance systems and inter-sectoral engagement with relevant ministries to promote public health interventions that prevent similar outbreaks occurrences in future.

\section{Abbreviations}

FGDs: Focus group discussions

Klls: Key Informant Interviews 
IDIs: In-depth Interviews

NWSC: National Water and Sewerage Corporation

VHTs: Village Health Teams

IMR: Interactive messaging response

IVR: Interactive voice response

SMS: Short messages

HMIS: Health Management information System

RRT: Rapid Response Team

\section{Declarations}

Ethics approval and consent to participate: The study was approved by the Uganda Ministry of Health. Further permission was sought from the district health offices and the management of the respective health facilities where the recovering patients were found. Study objectives, benefits and risks were explained to the study participants. We sought written informed consent from all study participants and endeavoured to observe confidentiality.

Consent for publication: Not applicable

Availability of data and materials: Not applicable

Competing interests: The authors declare that they have no competing interests

Funding: Ministry of Health (MOH), Uganda

Authors' contributions: LA and CNK designed the study. All authors participated in the implementation of the study including analysis. EA wrote the $1^{\text {st }} \mathrm{draft}$ of the manuscript and all authors reviewed and approved the final manuscript.

Acknowledgements: We acknowledge all the patients, health workers, and community leaders and members that participated in this study.

\section{Authors' information}

1. Christine Nalwadda Kayemba, MPH, Ph.D.

Senior Lecturer, Department of Community Health and Behavioural Sciences,

School of Public Health, College of Health Sciences, Makerere University 
Email: cnalwadda@musph.ac.ug

2. Lynn M. Atuyambe, MPH, PhD

Associate Professor, Department of Community Health and Behavioural Sciences,

School of Public Health, College of Health Sciences, Makerere University

Email: atuyambe@musph.ac.ug

3. Edwinah Atusingwize, BEHS, MPH

Research Associate, Department of Disease Control and Environmental Health,

School of Public Health, College of Health Sciences, Makerere University

Email: eatusingwize@musph.ac.ug

\section{References}

Alba, S., M. I. Bakker, M. Hatta, P. F. Scheelbeek, R. Dwiyanti, R. Usman, A. R. Sultan, M. Sabir, N.

Tandirogang and M. Amir (2016). "Risk Factors of Typhoid Infection in the Indonesian Archipelago." PloS one11(6): e0155286.

Alba, S., M. I. Bakker, M. Hatta, P. F. D. Scheelbeek, R. Dwiyanti, R. Usman, A. R. Sultan, M. Sabir, N. Tandirogang, M. Amir, Y. Yasir, R. Pastoor, S. van Beers and H. L. Smits (2016). "Risk Factors of Typhoid Infection in the Indonesian Archipelago." PLoS ONE11(6): e0155286.

Bunnell, R., D. O’Neil, R. Soler, R. Payne, W. H. Giles, J. Collins, U. Bauer and C. P. P. t. W. P. Group (2012). "Fifty communities putting prevention to work: accelerating chronic disease prevention through policy, systems and environmental change." Journal of community health37(5): 1081-1090.

Carias, C., M. S. Walters, E. Wefula, K. A. Date, D. L. Swerdlow, M. Vijayaraghavan and E. Mintz (2015). "Economic evaluation of typhoid vaccination in a prolonged typhoid outbreak setting: The case of Kasese district in Uganda." Vaccine33(17): 2079-2085.

Chitnis, A. S., P. S. Caruthers, A. K. Rao, J. Lamb, R. Lurvey, V. B. De Rochars, B. Kitchel, M. Cancio, T. J. Török, A. Y. Guh, C. V. Gould and M. E. Wise (2012). "Outbreak of Carbapenem-Resistant Enterobacteriaceae at a Long-Term Acute Care Hospital: Sustained Reductions in Transmission through Active Surveillance and Targeted Interventions." Infection Control \&\#x0026; Hospital Epidemiology33(10): 984-992.

Crawford, A. G., V. Sikirica, N. Goldfarb, R. G. Popiel, M. Patel, C. Wang, J. B. Chu and D. B. Nash (2005). "Interactive voice response reminder effects on preventive service utilization." American Journal of Medical Quality20(6): 329-336. 
Dillman, D. A., G. Phelps, R. Tortora, K. Swift, J. Kohrell, J. Berck and B. L. Messer (2009). "Response rate and measurement differences in mixed-mode surveys using mail, telephone, interactive voice response (IVR) and the Internet." Social Science Research38(1): 1-18.

Dowshen, N., L. M. Kuhns, C. Gray, S. Lee and R. Garofalo (2013). "Feasibility of interactive text message response (ITR) as a novel, real-time measure of adherence to antiretroviral therapy for HIV+ youth." AIDS and behavior17(6): 2237-2243.

Gadhoke, P., K. Christiansen, J. Swartz and J. Gittelsohn (2014). "'“'Cause it's family talking to you”: Children acting as change agents for adult food and physical activity behaviors in American Indian households in the Upper Midwestern United States." Childhood.

Gasem, M. H., W. Dolmans, M. Keuter and R. Djokomoeljanto (2001). "Poor food hygiene and housing as risk factors for typhoid fever in Semarang, Indonesia." Tropical Medicine \& International Health6(6): 484490.

Greenwell, J., J. McCool, J. Koolc and M. Salusalud (2013). "Typhoid fever: hurdles to adequate hand washing for disease prevention among the population of a peri-urban informal settlement in Fiji." Western Pacific surveillance and response journal: WPSAR4(1): 41-45.

Kabwama, S. N., L. Bulage, F. Nsubuga, G. Pande, D. W. Oguttu, R. Mafigiri, C. Kihembo, B. Kwesiga, B. Masiira, A. E. Okullo, H. Kajumbula, J. Matovu, I. Makumbi, M. Wetaka, S. Kasozi, S. Kyazze, M. Dahlke, P. Hughes, J. N. Sendagala, M. Musenero, I. Nabukenya, V. R. Hill, E. Mintz, J. Routh, G. Gómez, A. Bicknese and B.-P. Zhu (2017). "A large and persistent outbreak of typhoid fever caused by consuming contaminated water and street-vended beverages: Kampala, Uganda, January - June 2015." BMC Public Health17(1): 23.

Kim, J.-H., J. Im, P. Parajulee, M. Holm, L. M. Cruz Espinoza, N. Poudyal, O. D. Mogeni and F. Marks (2019). "A Systematic Review of Typhoid Fever Occurrence in Africa." Clinical infectious diseases : an official publication of the Infectious Diseases Society_ of America69(Suppl 6): S492-S498.

Manguvo, A. and B. Mafuvadze (2015). "The impact of traditional and religious practices on the spread of Ebola in West Africa: time for a strategic shift." The Pan African Medical Journal22(Suppl 1): 9.

Mbonye, A. K., J. F. Wamala, M. Nanyunja, A. Opio, I. Makumbi and J. R. Aceng (2014). "Ebola viral hemorrhagic disease outbreak in West Africa-lessons from Uganda." African health sciences14(3): 495501.

Mogasale, V., B. Maskery, R. L. Ochiai, J. S. Lee, V. V. Mogasale, E. Ramani, Y. E. Kim, J. K. Park and T. F. Wierzba (2014). "Burden of typhoid fever in low-income and middle-income countries: a systematic, literature-based update with risk-factor adjustment." Lancet Glob Health2(10): e570-580. 
Murphy, J., A. Kahler, I. Nansubuga, E. Nanyunja, B. Kaplan, N. Jothikumar, J. Routh, G. Gómez, E. Mintz and V. Hill (2017). "Environmental survey of drinking water sources in Kampala, Uganda, during a typhoid fever outbreak." Appl. Environ. Microbiol.83(23): e01706-01717.

Muti, M., N. Gombe, M. Tshimanga, L. Takundwa, D. Bangure, S. Mungofa and P. Chonzi (2014). "Typhoid outbreak investigation in Dzivaresekwa, suburb of Harare City, Zimbabwe, 2011." Pan African Medical Journal18(1).

Mwanga, J. R., B. B. Jensen, P. Magnussen and J. Aagaard-Hansen (2008). "School children as health change agents in Magu, Tanzania: a feasibility study." Health Promotion International23(1): 16-23.

Neil, K. P., S. V. Sodha, L. Lukwago, O. Shikanga, M. Mikoleit, S. D. Simington, P. Mukobi, S. Balinandi, S. Majalija and J. Ayers (2012). "A large outbreak of typhoid fever associated with a high rate of intestinal perforation in Kasese District, Uganda, 2008-2009." Clinical Infectious Diseases: cis025.

O’Connor, E., T. O’Sullivan, C. Amaratunga, P. Thille, K. Phillips, M. Carter and L. Lemyre (2009). "Risk communication with nurses during infectious disease outbreaks: Learning from SARS." Journal of Emergency Medicine7(5): 48-56.

Oh, S.-H., S. Y. Lee and C. Han (2020). "The Effects of Social Media Use on Preventive Behaviors during Infectious Disease Outbreaks: The Mediating Role of Self-relevant Emotions and Public Risk Perception." Health Communication: 1-10.

Onyango-Ouma, W., J. Aagaard-Hansen and B. Jensen (2005). "The potential of schoolchildren as health change agents in rural western Kenya." Social science \& medicine61(8): 1711-1722.

Osborn, C. Y. and S. A. Mulvaney (2013). "Development and feasibility of a text messaging and interactive voice response intervention for low-income, diverse adults with type 2 diabetes mellitus." Journal of diabetes science and technology.7(3): 612-622.

Prasad, N. (2015). Case control study to identify risk factors for typhoid fever in Central Division, Fijipreliminary results. 9th International Conference on Typhoid and Invasive NTS Disease.

Silwedel, C., U. Vogel, H. Claus, K. Glaser, C. P. Speer and J. Wirbelauer (2016). "Outbreak of multidrugresistant Escherichia coli sequence type 131 in a neonatal intensive care unit: efficient active surveillance prevented fatal outcome." Journal of Hospital Infection93(2): 181-186.

Stanaway, J. D., R. C. Reiner, B. F. Blacker, E. M. Goldberg, I. A. Khalil, C. E. Troeger, J. R. Andrews, Z. A. Bhutta, J. A. Crump, J. Im, F. Marks, E. Mintz, S. E. Park, A. K. M. Zaidi, Z. Abebe, A. N. Abejie, I. A. Adedeji, B. A. Ali, A. T. Amare, H. T. Atalay, E. F. G. A. Avokpaho, U. Bacha, A. Barac, N. Bedi, A. Berhane, A. J. Browne, J. L. Chirinos, A. Chitheer, C. Dolecek, M. El Sayed Zaki, B. Eshrati, K. J. Foreman, A. Gemechu, R. Gupta, G. B. Hailu, A. Henok, D. T. Hibstu, C. L. Hoang, O. S. Ilesanmi, V. J. Iyer, A. Kahsay, A. Kasaeian, T. D. Kassa, E. A. Khan, Y.-H. Khang, H. Magdy Abd El Razek, M. Melku, D. T. Mengistu, K. A. Mohammad, S. 
Mohammed, A. H. Mokdad, J. B. Nachega, A. Naheed, C. T. Nguyen, H. L. T. Nguyen, L. H. Nguyen, N. B. Nguyen, T. H. Nguyen, Y. L. Nirayo, T. Pangestu, G. C. Patton, M. Qorbani, R. K. Rai, S. M. Rana, C. L. Ranabhat, K. T. Roba, N. L. S. Roberts, S. Rubino, S. Safiri, B. Sartorius, M. Sawhney, M. S. Shiferaw, D. L. Smith, B. L. Sykes, B. X. Tran, T. T. Tran, K. N. Ukwaja, G. T. Vu, L. G. Vu, F. Weldegebreal, M. K. Yenit, C. J. L. Murray and S. I. Hay (2019). "The global burden of typhoid and paratyphoid fevers: a systematic analysis for the Global Burden of Disease Study 2017." The Lancet Infectious Diseases19(4): 369-381.

Tambo, E., E. C. Ugwu and J. Y. Ngogang (2014). "Need of surveillance response systems to combat Ebola outbreaks and other emerging infectious diseases in African countries." Infectious Diseases of Poverty3(1): 29.

Tang, L., B. Bie, S.-E. Park and D. Zhi (2018). "Social media and outbreaks of emerging infectious diseases: A systematic review of literature." American Journal of Infection Control46(9): 962-972.

Tumwebaze, I. K., C. G. Orach, C. Niwagaba, C. Luthi and H.-J. Mosler (2013). "Sanitation facilities in Kampala slums, Uganda: users' satisfaction and determinant factors." International journal of environmental health research23(3): 191-204.

UBOS (2015). "National population and housing census, 2014."

Vanessa, N. and B. Matthias (2012). "Infection control during filoviral hemorrhagic fever outbreaks." Journal of Global Infectious Diseases4(1): 69-74.

Vollaard, A. M., S. Ali, H. A. van Asten, S. Widjaja, L. G. Visser, C. Surjadi and J. T. van Dissel (2004). "Risk factors for typhoid and paratyphoid fever in Jakarta, Indonesia." Jama291(21): 2607-2615.

Walters, M. S., J. Routh, M. Mikoleit, S. Kadivane, C. Ouma, D. Mubiru, B. Mbusa, A. Murangi, E. Ejoku, A. Rwantangle, U. Kule, J. Lule, N. Garrett, J. Halpin, N. Maxwell, A. Kagirita, F. Mulabya, I. Makumbi, M. Freeman, K. Joyce, V. Hill, R. Downing and E. Mintz (2014). "Shifts in Geographic Distribution and Antimicrobial Resistance during a Prolonged Typhoid Fever Outbreak - Bundibugyo and Kasese Districts, Uganda, 2009-2011." PLoS Negl Trop Dis8(3): e2726.

Watson, C., B. Basnyat, F. Martineau, G. Kang, S. Baker, J. Meiring and V. Pitzer "The Invisible Burden: Diagnosing and Combatting Typhoid Fever in Asia and Africa." Clinical Infectious Diseases69(Supplement_5): S395-S401.

WHO. (2015). "Emergencies preparedness, response-Typhoid fever - Uganda." Retrieved 30th October, 2016.

WHO. (2018). "Immunization, Vaccines and Biologicals: Typhoid " Retrieved 25th Feb, 2019, from https://www.who.int/immunization/diseases/typhoid/en/.

\section{Figures}




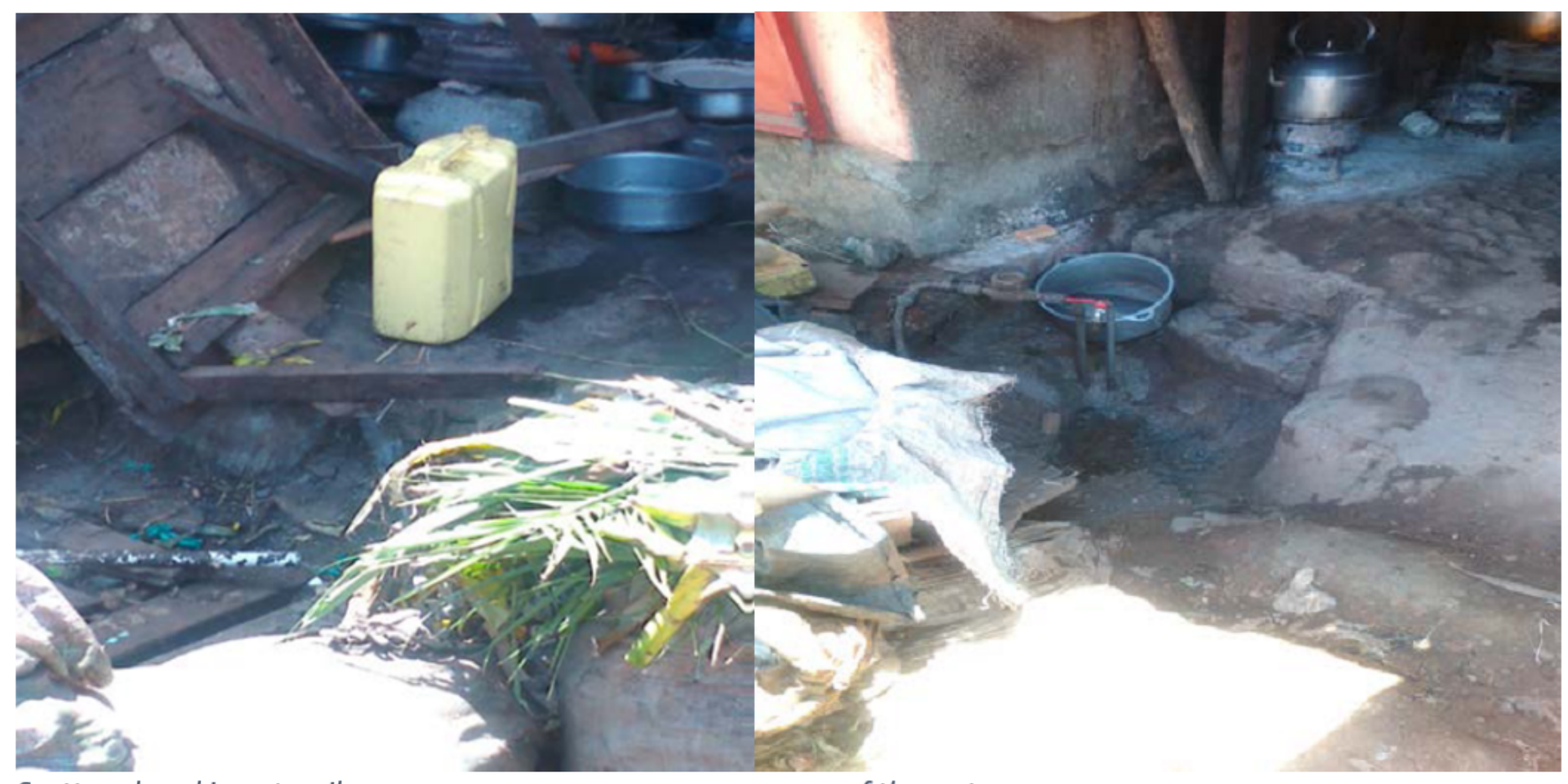

some of the water sources

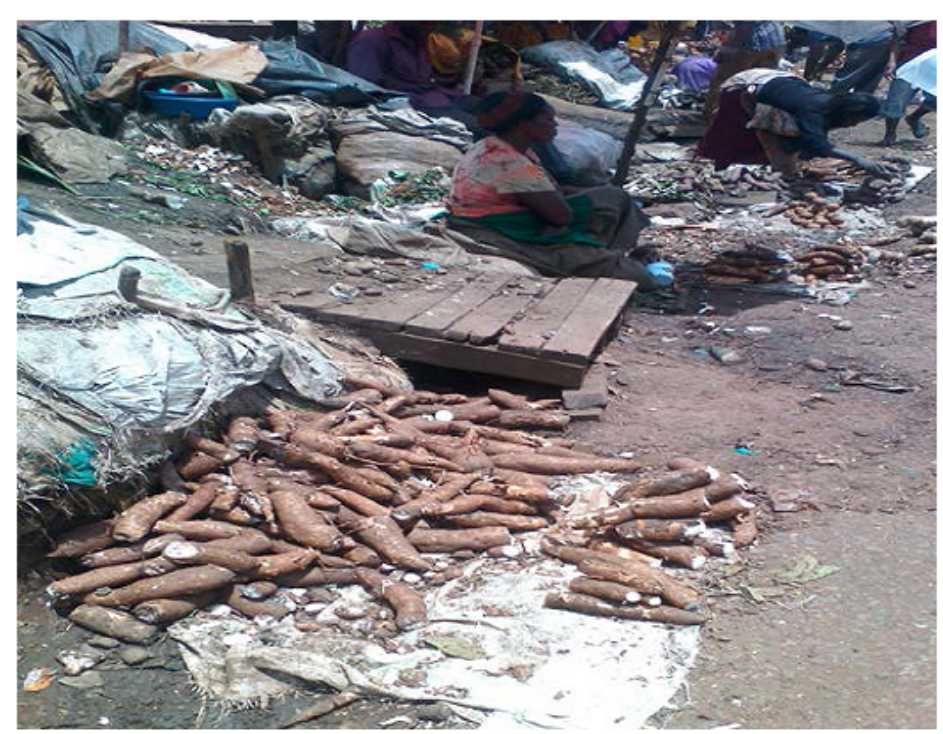

Market littered with solid waste

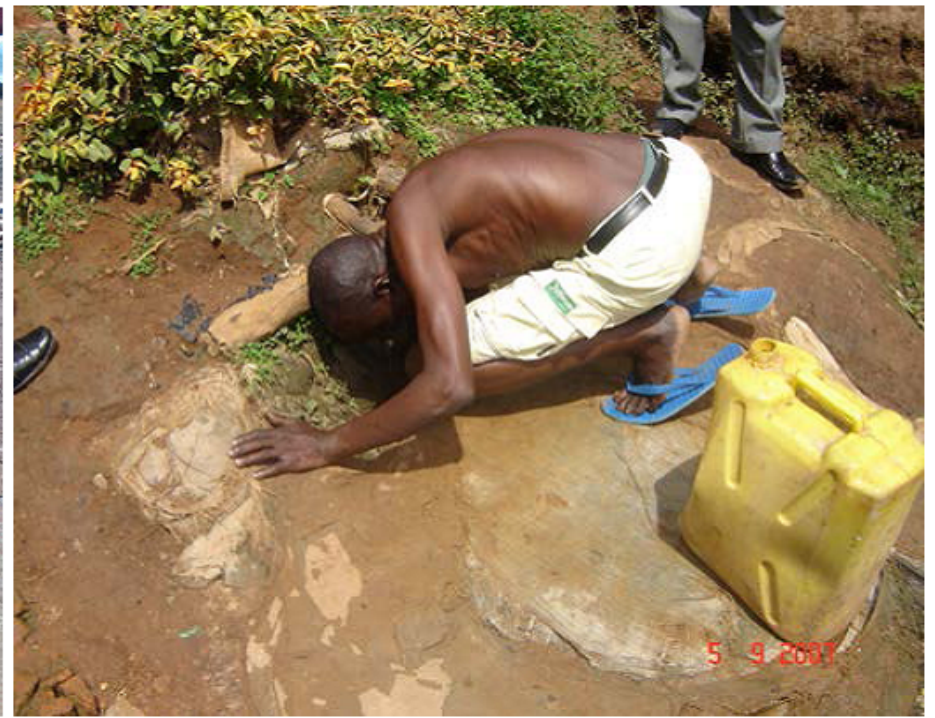

Open shallow well

Figure 1

Selected pictures from environmental observations 